\title{
Reconstituted normal human breast in nude mice: effect of host pregnancy environment and human chorionic gonadotropin on proliferation
}

\author{
N Popnikolov ${ }^{1}$, J Yang ${ }^{1,2}$, A Liu ${ }^{1,2}$, R Guzman ${ }^{1}$ and S Nandi ${ }^{1}$ \\ ${ }^{1}$ Cancer Research Laboratory and Department of Molecular and Cell Biology, University of California, Berkeley, California 94720, USA \\ ${ }^{2}$ Cancer Research Fund of Contra Costa, 210 Mississippi Street, San Francisco, California 94107, USA \\ (Requests for offprints should be addressed to J Yang) \\ (N Popnikolov is now at the Department of Pathology, University of Texas Medical Branch, Galveston, Texas, USA)
}

\begin{abstract}
The proliferation of normal human breast epithelial cells in women is highest during the first trimester of pregnancy. In an attempt to analyze this hormonal environment in a model system, the effect of host mouse pregnancy and the administration of human chorionic gonadotropin (hCG) were assessed in normal human breast epithelial cells transplanted into athymic nude mice. Human breast epithelial cells, dissociated from reduction mammoplasty specimens and embedded inside the extracellular matrices comprised of collagen gel and Matrigel, were transplanted into nude mice. Proliferation was measured in vivo by BrdU labeling followed by immunostaining of sections from recovered gels in response to an altered hormonal environment of the host animal. The host animal was mated to undergo pregnancy and the complex hormonal environment of the host animal pregnancy stimulated growth of transplanted human cells. This effect increased with progression of pregnancy and reached the maximum during late pregnancy prior to parturition. In order to determine whether additional stimulation could be achieved, the transplanted human cells were exposed to a second cycle of host mouse pregnancy by immediately mating the animal after parturition. This additional
\end{abstract}

exposure of host mouse pregnancy did not result in further increase of proliferation. The effect of hCG administration on transplanted human cells was also tested, since hCG level is highest during the first trimester of human pregnancy and coincides with the maximal breast cell proliferation. Administration of hCG alone stimulated proliferation of human cells in a dose-dependent manner, and could further enhance stimulation achieved with estrogen. The host mouse mammary gland also responded to hCG treatment resulting in increased branching and lobulo-alveolar development. However, the hCG effect on both human and mouse cells was dependent on intact ovary since the stimulation did not occur in ovariectomized animals. Although hCG receptor transcripts were detected in human breast epithelial cells, raising the possibility of a direct mitogenic action, the hCG effect observed in this study may have been mediated via the ovary by increased secretion of ovarian steroids. In summary, using our in vivo nude mice system, the proliferation of normal human breast epithelial cells could be stimulated by host mouse pregnancy and by administration of hCG. Journal of Endocrinology (2001) 168, 487-496

\section{Introduction}

Proliferation of human breast epithelial cells throughout a woman's life is under the control of various hormones (Imagawa et al. 1990, 1994, Pike et al. 1993). During a normal menstrual cycle, normal breast epithelial cell proliferation is greatest during the luteal phase when both $17 \beta$-estradiol and progesterone levels are high. However, by far the highest proliferation is seen during the first trimester in pregnancy when there is extensive branching of the ducts as well as development of alveoli. Rodent studies have demonstrated that periods of maximum proliferation during pregnancy can be correlated with periods of high progesterone and prolactin or placental lactogen production from ovaries, placenta, and anterior pituitary. For the human breast, it has been difficult to determine the role of various hormones as well as growth factors on the proliferation of breast epithelial cells during pregnancy. A variety of endocrinological changes occur during pregnancy, including variations 
in estrogen, progesterone, glucocorticoid, prolactin and placental lactogen. Of particular interest is human chorionic gonadotropin (hCG), which reaches the maximal plasma level during the first trimester and coincides in time with the greatest growth of breast epithelial cells.

Apart from clinical studies directly involving patients, approaches to studying normal human breast epithelial cells are rather limited. The hormonal changes of pregnancy are too complex to mimic by addition of exogenous hormones in the organ culture or the primary cell culture systems. An alternative approach is the in vivo nude mice system which has been utilized to a limited extent for the transplantation of non-cancerous or normal human breast tissues from surgical specimens (Jensen \& Wellings 1976, Gusterson et al. 1984, McManus \& Welsch 1984, Laidlaw et al. 1995). In the in vivo system, the host mouse can be mated to undergo pregnancy and the effect on the transplanted human breast epithelial cells can be determined (Gusterson et al. 1984). Although the hormonal milieu in human pregnancy is certainly different from that in mouse pregnancy, the complex mixture of hormones may be better mimicked in this manner rather than by the administration of known hormones.

We have previously reported the transplantation of collagen gel embedded human breast epithelial cells, dissociated from surgical breast specimens, into nude mice (Yang et al. 1994). In this system, the dissociated cells undergo morphogenesis to reflect their original phenotypes. When cancer cells from mastectomy specimens are transplanted, the histological sections of recovered gels showed outgrowths with invasive pattern. When normal cells from reduction mammoplasty specimens are used, histological sections of recovered gels showed epithelial cells arranged as tubular structures consisting of lumina surrounded by epithelial cells and embedded in what was once the collagen gel but now resembled collagenous stroma with fibroblasts and vascular channels. The transplanted human breast epithelial cells also retain both estrogen and progesterone receptors which can be regulated in response to administration of exogenous estrogen (Yang et al. 2000a). Using this in vivo system, the proliferation of normal human breast epithelial cells in response to administration of hormones and growth factor was analyzed (Popnikolov et al. 1995a,b). Higher dosage of estrogen administration was required to stimulate the proliferation of human breast cells compared with the host mouse mammary epithelial cells. Growth factors such as the epidermal growth factor and cholera toxin, previously shown to be mitogenic in culture system (Yang et al. 1987), also stimulated proliferation in vivo and had an additive effect with estrogen (Popnikolov et al. 1995). In this study, we report the effect of host mouse pregnancy as well as exogenous administration of hCG on transplanted human breast epithelial cells.

\section{Materials and Methods}

\section{Cell dissociation}

A total of 10 reduction mammoplasty specimens from donors aged 15-38 years were obtained from the Cooperative Human Tissue Network (Columbus, OH, USA). Specimens placed in medium were received via overnight delivery and processed within $36 \mathrm{~h}$ of receipt. Enzymatic dissociation of the human breast tissue and preparation of collagen gel were performed as described previously (Yang et al. 1994, Popnikolov et al. 1995a). Approximately $0.5 \mathrm{ml}$ ice-cold $1: 1$ mixture of rat tail collagen and Matrigel containing $10-30 \times 10^{6}$ human breast epithelial cells were pipetted into a 24 -well plate, allowed to gel at room temperature, and immediately used for transplantation. All experiments utilized cells embedded in 1:1 mixture except in one experiment where cells were embedded only in collagen gel. A previous paper which compared the collagen gel and Matrigel culture systems has shown similar result in terms of proliferative response to hormones (Popnikolov et al. 1995b).

\section{Transplantation}

Transplantation of the gels into 2-3-month-old female virgin nude mice was performed as previously described (Popnikolov et al. 1995a,b). Briefly, a gel containing the cells was transplanted subcutaneously on each dorsolateral side of each mouse. Each reduction mammoplasty specimen was transplanted into 6-18 mice. For pregnancy studies, the nude mice following transplantation were immediately mated with $\mathrm{BALB} / \mathrm{c}$ males. The mice were terminated at different intervals after mating. The exact stage of pregnancy was determined by measuring the size of the embryos (Rugh 1990). For hCG studies, the nude mice after transplantation were given different treatments: (1) control - no treatment or cholesterol pellets $(5 \mathrm{mg})$ implanted subcutaneously, (2) Silastic capsules containing $2 \mathrm{mg} 17 \beta$-estradiol $+18 \mathrm{mg}$ progesterone implanted subcutaneously at the time of transplantation, (3) 25 IU or 75 IU hCG (Sigma, St Louis, MO, USA) dissolved in medium 199 injected subcutaneously in the dorsal area two times daily for 5-7 days starting 10-14 days after transplantation, (4) cholesterol pellets containing hCG (1000 IU) implanted for 3 days 10-14 days after transplantation, (5) $17 \beta$-estradiol+progesterone administrated by Silastic capsules + hCG injection as described above, (6) ovariectomy performed at the time of transplantation+hCG injections or pellets as described above. In one experiment, mice were treated with hCG 15 weeks after transplantation. In all experiments, proliferation was quantitated in vivo by $2 \mathrm{~h}$ pulse labeling with 5-bromo-2'-deoxy-uridine $(160 \mathrm{mg} / \mathrm{g}$ body weight) and immunostaining of sections from recovered gels. 


\section{Immunohistochemistry}

The recovered gels and host mouse mammary glands were fixed in methacarn and processed for histology using standard procedure at Pathology Services Inc. of Alta Bates Hospital, Berkeley, CA, USA as previously described (Popnikolov et al. 1995a,b). Both hematoxylin-eosin stained section and unstained section for immunostaining of BrdU labeled cells were obtained. Briefly, the deparaffinized sections were treated with $2 \mathrm{M} \mathrm{HCl}$ for $1 \mathrm{~h}$ at $40{ }^{\circ} \mathrm{C}$ to partially denature the cellular DNA. The sections were incubated with $3 \% \mathrm{H}_{2} \mathrm{O}_{2}$, washed in PBS, and subsequently covered with non-immunized rabbit serum for $10 \mathrm{~min}$. A primary monoclonal rat antibody to BrdU (Accurate, San Diego, CA, USA) diluted 1:5 in 0.5\% BSA was applied for $1 \mathrm{~h}$ at room temperature. The sections were then incubated with biotinylated secondary rabbit anti-rat IgG antibody and avidin-biotin complex (Vectastain ABC Kit, Vector Labs, CA, USA). The BrdU-labeled cells were visualized using $0 \cdot 15 \% \mathrm{H}_{2} \mathrm{O}_{2}$ / $0.05 \%$ diaminobenzidine tetrahydrochloride (DAB) in PBS. The sections were finally counterstained with hematoxylin. The percentage of labeled cells (labeling index) was determined by counting 2000-10000 cells per gel. Statistical analysis of labeling indices was performed using Student's $t$-test.

\section{Reverse-transcription polymerase chain reaction (RT-PCR)}

Total RNA from the normal human breast epithelial cells dissociated from six reduction mammoplasty specimens were extracted using the SNAP Total RNA Isolation Kit (InVitrogen, Carlsbad, CA, USA) following the manufacturer's protocol. Total RNA were pooled and analyzed for the presence of hCGR using reverse-transcription polymerase chain reaction (RT-PCR). Reverse transcription of the pooled RNA from surgical specimens was performed using the Thermoscript RT-PCR System (Life Technologies, Inc., Rockville, MD, USA) according to the manufacturer's directions as previously reported (Yang et al. 2000b). Briefly, varying quantities of RNA in a total volume of $9 \mu \mathrm{l}$ were denatured at $65^{\circ} \mathrm{C}$ for $5 \mathrm{~min}$ with $10 \mathrm{pmol}$ of the downstream primer, hLH-RD $5^{\prime}$-TGG CAT GGT TAT AGT ACTG GC-3' in a total volume of $10 \mu \mathrm{l}$. A $9 \mu \mathrm{l}$ volume of Thermoscript reaction mix (consisting of $15 \mathrm{U}$ Thermoscript RT, 5X cDNA Synthesis Buffer, 0.1 M DTT, $10 \mathrm{mM}$ dNTP Mix, $40 \mathrm{U}$ RNase Out, DEPC-treated water) was added to make a total volume of $19 \mu \mathrm{l}$. RT was performed at $50^{\circ} \mathrm{C}$ for $50 \mathrm{~min}$ and terminated by heating at $85^{\circ} \mathrm{C}$ for $5 \mathrm{~min}$. Any residual RNA was digested with $1 \mu \mathrm{l}$. coli RNase H (40 U) and incubated at $37^{\circ} \mathrm{C}$ for $20 \mathrm{~min}$. The cDNA product was immediately used for PCR amplification.

Using the Perkin-Elmer 4800 Thermocycler, nested and semi-nested PCR amplifications of hCGR were performed on the cDNA product using the HotStarTaq
Master Mix Kit (Qiagen Inc., Valencia, CA, USA). The PCR reaction was carried out in a final volume of $50 \mu \mathrm{l}$ consisting of $25 \mu \mathrm{l}$ of HotStarTaq Master Mix (2.5 U HotStarTaq DNA Polymerase, 1X PCR Buffer, $200 \mathrm{mM}$ of each dNTP), $10 \mathrm{pmol}$ of each primer, and $10 \mu \mathrm{l}$ of the cDNA preparation. A pair of external primers consisting of a forward primer, hLH-RU 5'-CTT GGA TAT TTC TTC CAC CAA A-3' (686-707), and a reverse primer, hLH-RD 5'-TGG CAT GGT TAT AGT ACT GGC-3' (1279-1299), were used in the first round PCR amplification, yielding a $615 \mathrm{bp}$ product. The PCR reaction was activated at $95^{\circ} \mathrm{C}$ for $15 \mathrm{~min}$ and ran for 38 cycles of denaturation $\left(94^{\circ} \mathrm{C}, 30 \mathrm{~s}\right)$, annealing $\left(58^{\circ} \mathrm{C}, 50 \mathrm{~s}\right)$, and extension $\left(72{ }^{\circ} \mathrm{C}, 1 \mathrm{~min}\right)$. Second round PCR amplifications using the same conditions as the first cycle were subsequently performed using $10 \mu \mathrm{l}$ of the 1:100 dilution of the first round PCR product. Three separate second cycle PCR amplifications were performed by using three combinations of primers. A nested PCR amplification was performed using the forward primer, hCG-RU 5'-CAG CCA CTG CTG TGC TTT TAG AA-3' (836-858), and the reverse primer, hCG-RD 5'-AGC CAA ATC AGG ACC CTA AGG AA-3' (1089-1111), yielding a 275 bp product. A semi-nested PCR using the forward primer from the first round of PCR (hLH-RU) in combination with the reverse primer from the nested PCR (hCG-RD) was performed, yielding a $435 \mathrm{bp}$ product. Another seminested PCR amplification using the forward primer from the nested PCR (hCG-RU) in combination with the reverse primer from the first round PCR (hLH-RD) was performed, yielding a $455 \mathrm{bp}$ product. All primers used in this study have been previously reported (Lojun et al. 1997, Meduri et al. 1997). The sequence numberings are based on the published sequence of the hCG receptor (M63108). The PCR products were subjected to electrophoresis on a $2 \cdot 0 \%$ agarose gel, stained with Gelstar (FMC Bioproducts, Rockland, ME, USA), and photographed.

For sequencing, the PCR products were gel purified using the QIAquick Gel Extraction Kit (Qiagen Inc.) following the manufacturer's instruction. Direct sequencing of the PCR products were performed using BigDye Terminator Ready Reaction Mix (PE Biosystems, Foster City, CA, USA) and Applied Biosystems 377 Sequencer (Perkin-Elmer) by the DNA Sequencing Facility of the University of California, Berkeley.

\section{Results}

\section{Proliferation in response to host mouse pregnancy}

The histomorphology and proliferation of human breast epithelial cells in response to host mouse pregnancy was examined using three reduction mammoplasty specimens. The histological sections from recovered collagen gels showed human breast epithelial cells arranged as short tubular structures with occasionally more complex 


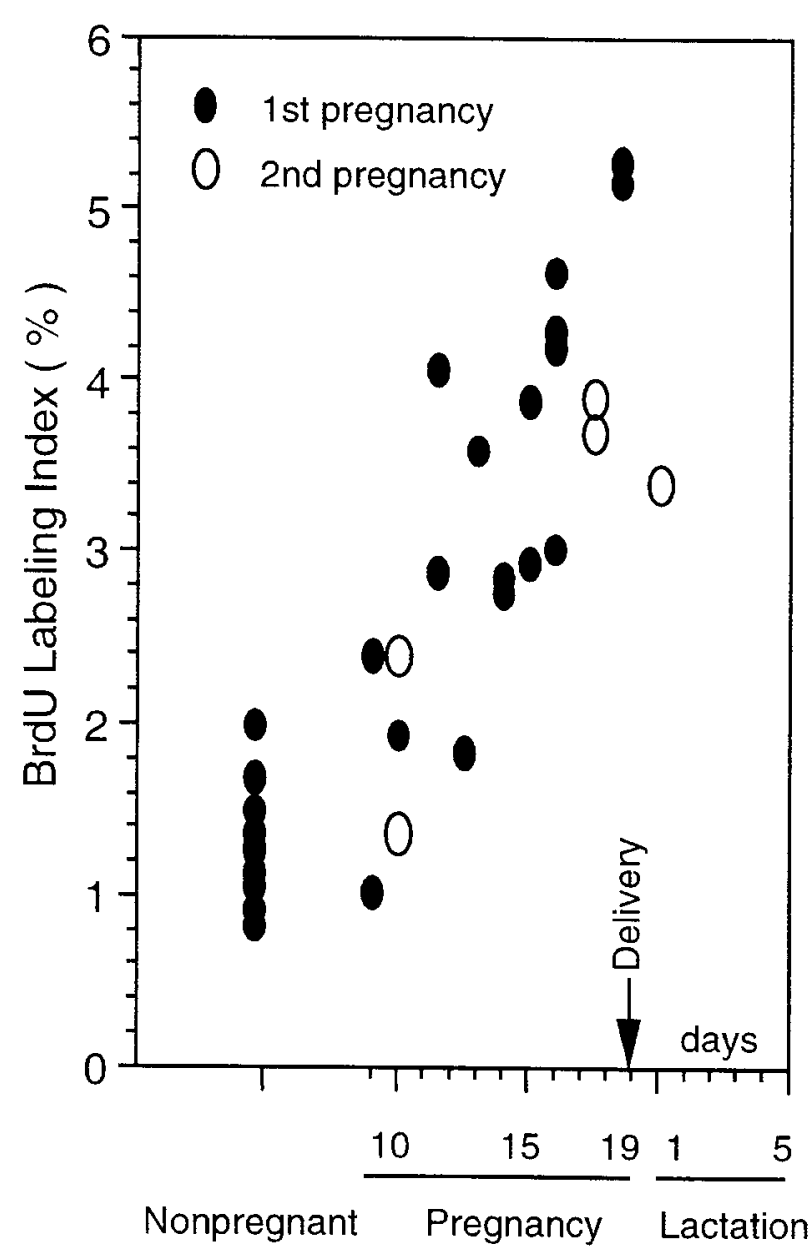

Figure $1 \mathrm{BrdU}$ labeling indices (\%) of transplanted human breast epithelial cells at various points during host nude mice pregnancy. The graph represents the combined data from three independent experiments.

branching structures. No histomorphological difference was noted between the cells from the control group and from the pregnant group. However, when proliferation was quantitated by immunostaining of BrdU-labeled cells, an increased labeling was seen in cells from the pregnant group. Further analysis showed that the labeling index of transplanted human cells increased through host mouse pregnancy and the highest proliferation was seen during late pregnancy (Figs 1 and 2C). In order to determine whether further stimulation can be obtained, the exposure of human cells to another cycle of host mouse pregnancy was achieved by an immediate and successive pregnancy of the host mouse right after parturition. The human breast cells from recovered gels, however, did not show any difference from that seen in cells from the first pregnancy in terms of histomorphology. BrdU labeling index also showed no difference and in fact revealed a very similar pattern to that seen during the first pregnancy (see open symbols in Fig. 1).

\section{Proliferation in response to hCG alone}

The effect of hCG on proliferation of human breast epithelial cells was examined using seven reduction mammoplasty specimens. Human CG was administered either by daily injections or by implantation of cholesterol pellets. When injected at a dose of $50 \mathrm{IU} /$ day, a definite increase in proliferation was seen in all three specimens (Fig. 3), although no morphological change was evident (Fig. 2E). This hCG effect on proliferation was even seen when the hormone was administered 15 weeks after transplantation (Expt 2 in Fig. 3). A higher dose of 150 IU hCG/day was also tested in one experiment (Expt 1 in Fig. 3) to determine whether further stimulation could be elicited, but the stimulation in fact was less than that seen with 50 $\mathrm{IU} /$ day $(1 \cdot 80 \pm 0 \cdot 4 \%$ for $150 \mathrm{IU} /$ day vs $2 \cdot 84 \pm 0 \cdot 44 \%$ for $50 \mathrm{IU} /$ day). Host mouse mammary glands were greatly stimulated by treatment with hCG. Morphologically, ductal branching and lobulo-alveolar developments were evident (Fig. 2D), and BrdU uptake studies have shown increased labeling index. An increased number of corpora lutea was also seen in ovaries of the hCG-treated mice.

When hCG was administered by implantation of hCG pellet and proliferation assessed after 3 days, the maximal stimulation was seen at a dose of 1000 IU (Fig. 4). The lower dose and the higher dose elicited less stimulation, suggesting that a dose of 1000 IU was the optimal concentration under our experimental conditions.

\section{Proliferation in response to both hCG and ovarian steroids}

We previously reported that the ovarian steroids $(17 \beta-$ estradiol and progesterone) greatly stimulated proliferation of human breast epithelial cells using the same in vivo nude mice system used in this study. The optimal dose of hCG was administered on top of the ovarian steroids at doses previously determined to elicit maximal stimulation of proliferation (Popnikolov et al. 1995a,b). Addition of hCG on top of ovarian steroids elicited a moderate increase in stimulation in two of the three experiments (Fig. 5). The results of these experiments prompted us to perform two sets of additional experiments in order to help determine whether hCG may be acting directly at the breast epithelial cell level, or acting indirectly through the ovaries via secretion of ovarian steroids.

\section{Effect of ovariectomy on hCG-induced stimulation}

Since hCG stimulates the secretion of ovarian steroids from human and rodent ovaries, experiments were performed to determine whether the growth stimulation elicited by hCG will also take place using ovariectomized animals. When ovariectomized animals were used, hCG did not induce stimulation in human breast epithelial cells (Fig. 6) 

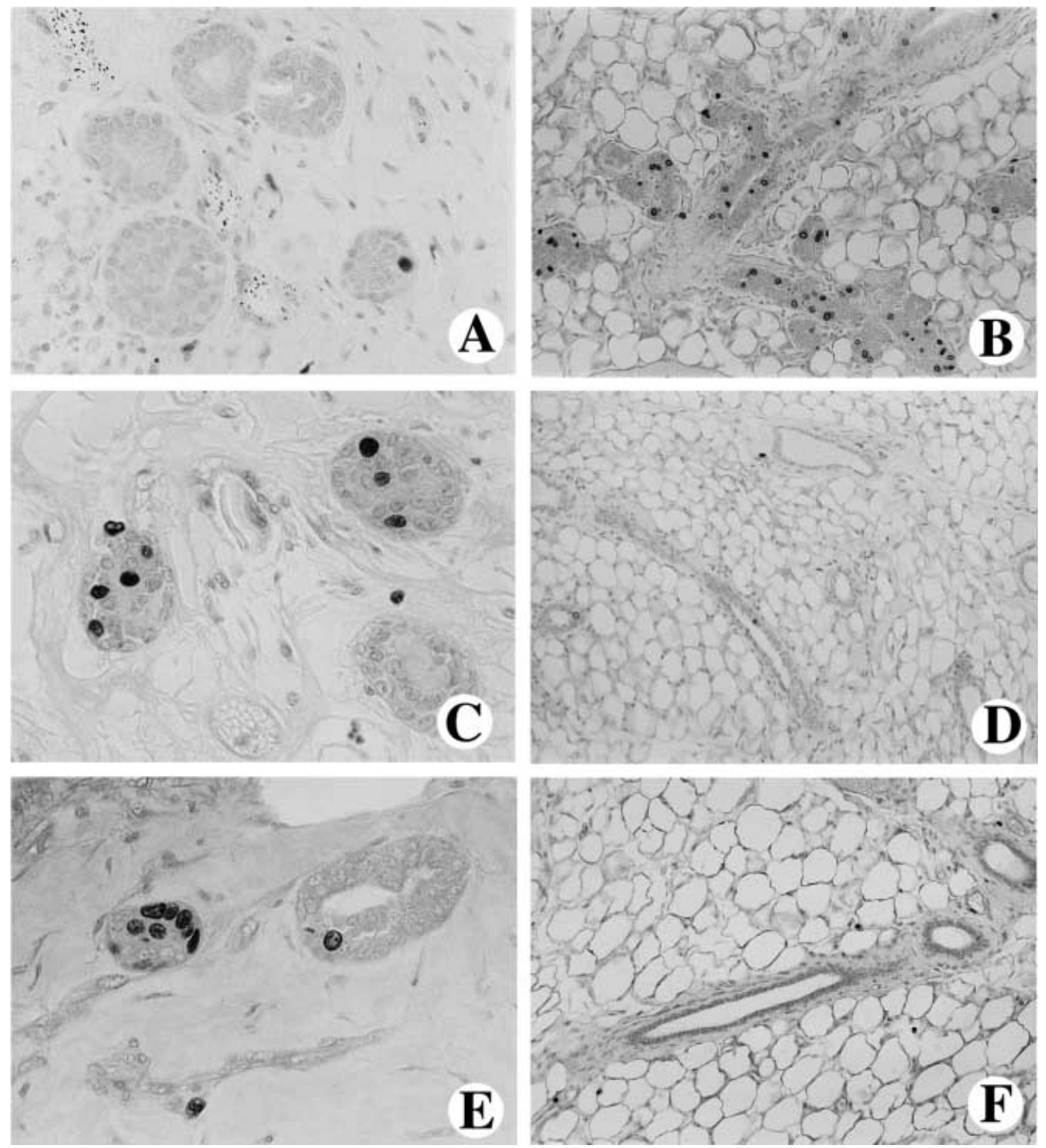

Figure 2 Histomorphology and proliferation assessed by BrdU immunostaining of transplanted human breast epithelial cells (A, C, E) and host mouse mammary gland (B, D, F). Human breast epithelial cells recovered from control mouse (A), from mouse at day 14 of pregnancy (C), and from mouse treated with hCG (1000 IU/pellet) for 3 days (E). Note increased labeling in $\mathrm{C}$ and $\mathrm{E}$ (also note mitotic figure in the center) compared with $\mathrm{A}$. Host mouse mammary gland of intact mouse (D), intact mouse treated with $50 \mathrm{IU} \mathrm{hCG/day} \mathrm{for} 7$ days (B), and ovariectomized mouse treated with $50 \mathrm{IU}$ hCG/day for 7 days (F). Note increased labeling, branching and lobulo-alveolar development of mouse mammary gland in B, but not in F. A, C, E : × 240. B, D, F : × 120.

nor in host mouse mammary glands (Fig. 2F). The stimulatory effect of hCG seems to depend on the presence of intact ovaries in the host mouse.

\section{hCG receptors in human breast epithelial cells}

In order to determine whether hCG could directly act at the breast epithelial cell level, highly enriched breast epithelial cells from reduction mammoplasty specimens were isolated using the Percoll gradient centrifugation. This preparation was used to determine the presence of hCG receptor transcripts using three different semi-nested PCR combinations (Fig. 7A). The PCR products were all of the expected size, and moreover the direct sequencing of the PCR products showed an identical sequence to the published hCG receptor sequence (data not shown). The 


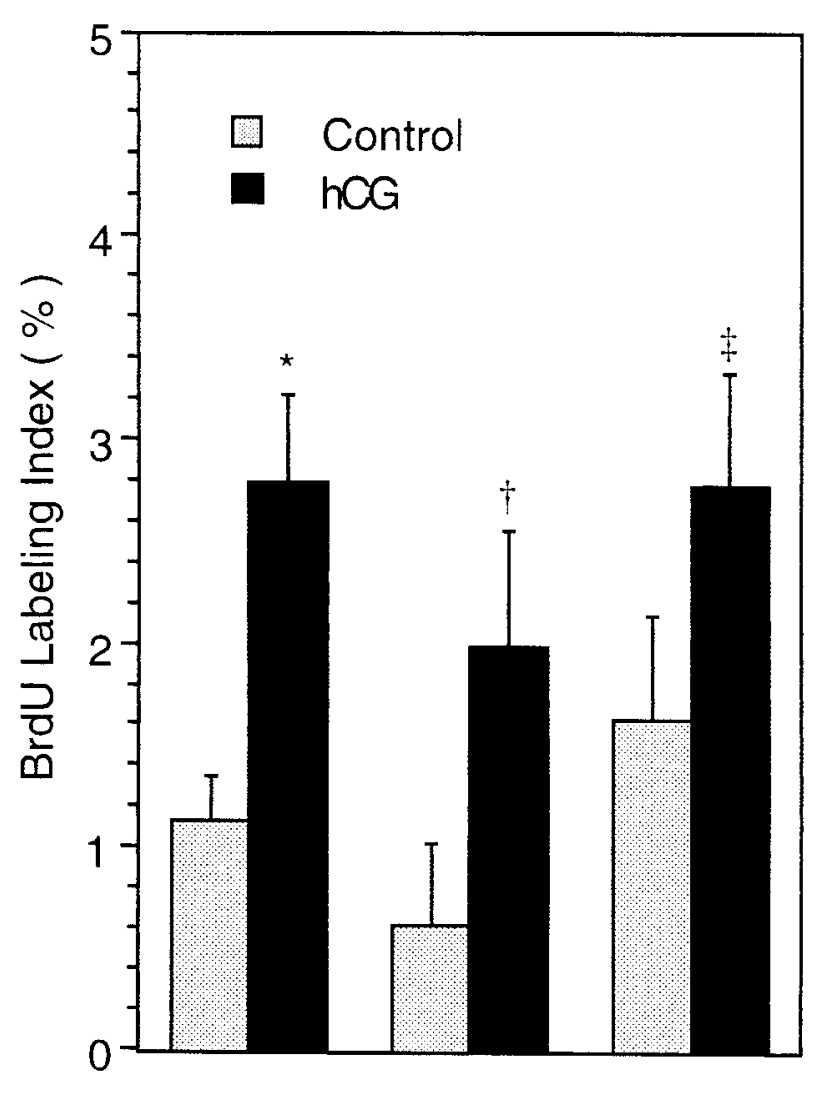

Expt 1 Expt 2 Expt 3

Figure 3 Effect of hCG injections (50 IU/day for 5-7 days) on BrdU labeling indices (\%) of human breast epithelial cells transplanted into nude mice. Each bar represents the mean \pm S.D. of values from three to seven gels. * Significantly greater than corresponding control $(P<0 \cdot 001)$; †significantly greater than corresponding control $(P<0 \cdot 005)$; $\ddagger$ significantly greater than corresponding control $(P<0 \cdot 025)$.

nested RT-PCR was then used to demonstrate hCG receptor transcripts in epithelial cells from six separate reduction mammoplasty specimens (Fig. 7B). The results demonstrate that the hCG receptor transcripts are in fact present in normal human breast epithelial cells.

\section{Discussion}

There is a paucity of information on the hormonal regulation of proliferation in normal human breast. Breast epithelial cells undergo proliferation throughout a woman's life under the control of various hormones. Although the highest proliferation is seen during the first trimester of pregnancy, it is not known which combination of hormones are responsible for this sustained growth. Animal studies have demonstrated the importance

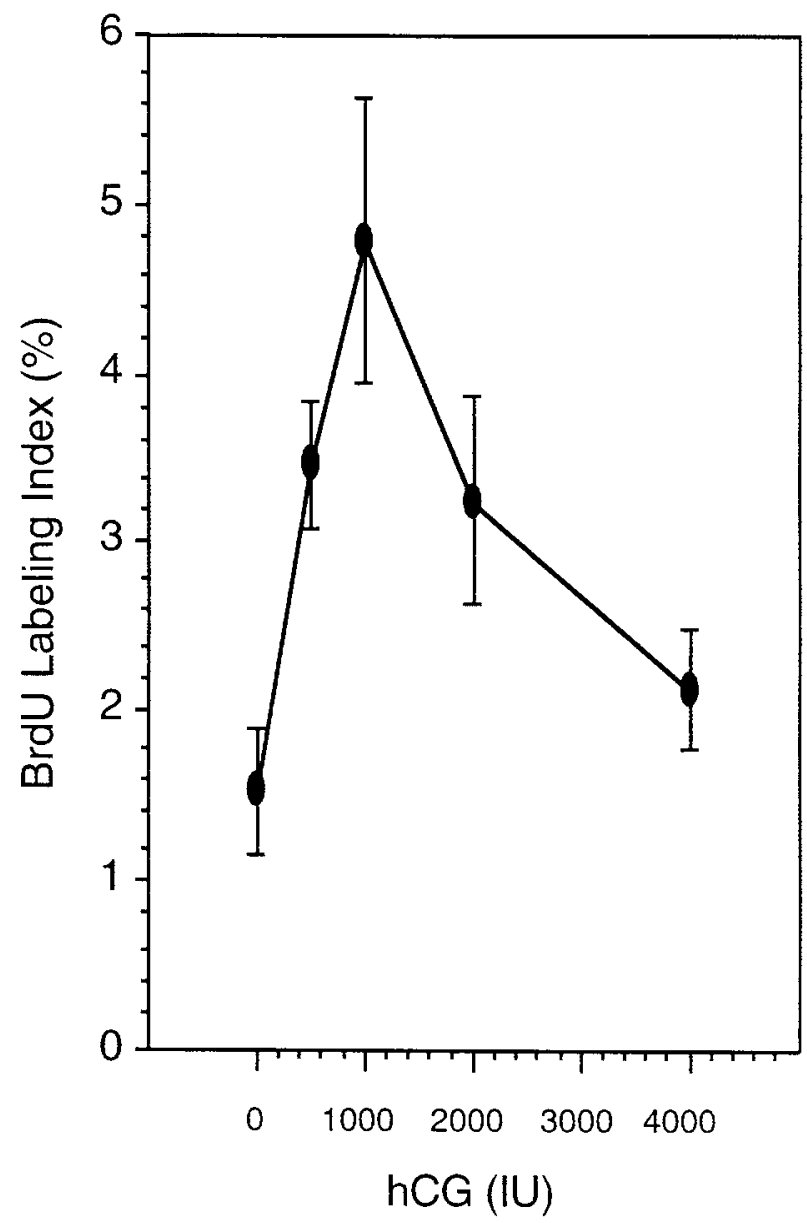

Figure 4 Dose-response of hCG administered as pellet on BrdU labeling indices (\%) of human breast epithelial cells transplanted into nude mice. Each point represents the mean \pm S.D. of combined data from three independent experiments.

of both steroid hormones and pituitary hormones, but direct evidence for this is lacking in humans. Approaches to studying normal human breast are rather limited, essentially confined to clinical studies directly involving patients (Soderqvist et al. 1993) and studies utilizing surgical materials with subsequent stratification based on patient characteristics (Williams et al. 1991). The former approach is limited in that the normal breast epithelial cells are not readily accessible, except with fine needle aspiration, and the hormonal studies involving administration of exogenous hormones to patients cannot be easily done. The latter, though providing invaluable information, is essentially a correlation and further studies are necessary to establish a causal relationship. An alternate and a more direct approach is an experimental one utilizing the transplantation of normal human breast tissues into athymic nude mice and assessing the effect of altered hormonal milieu on proliferation. However, the technical 


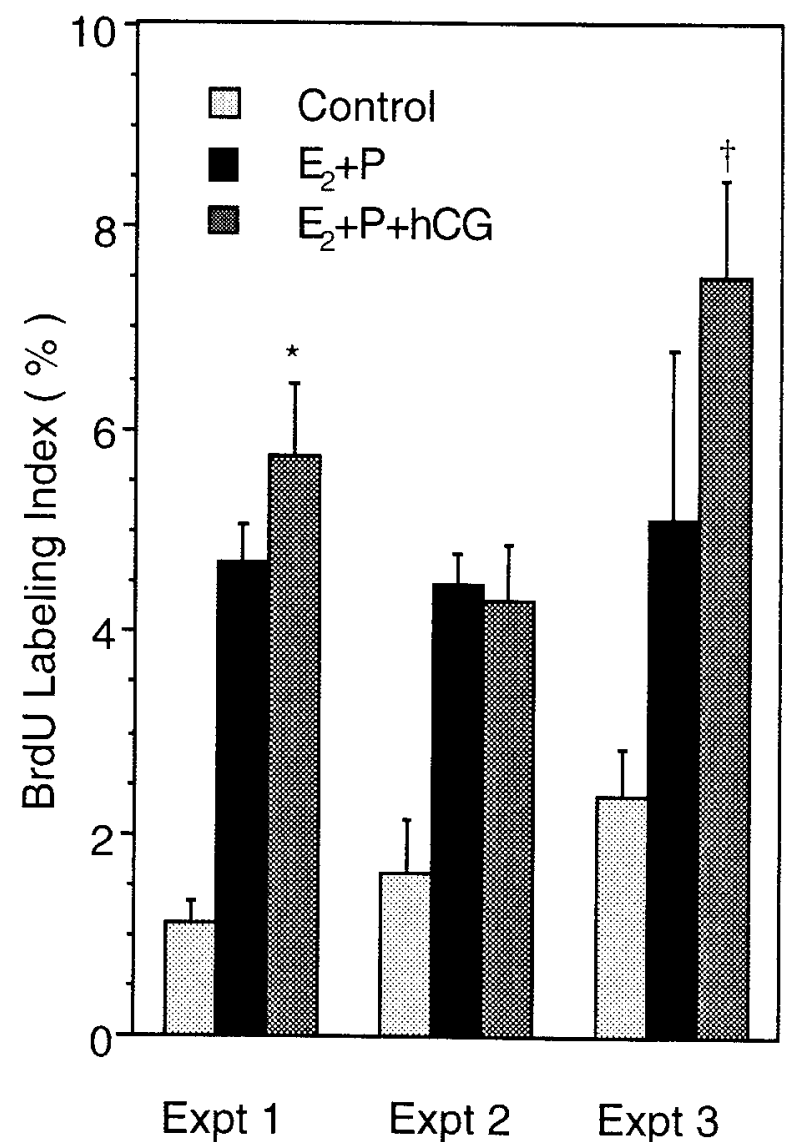

Figure 5 Effect of hCG administration on ovarian steroids induced proliferation of human breast epithelial cells transplanted into nude mice. Each bar represents the mean \pm S.D. of values from three to seven gels. *Significantly greater than ovarian steroids treated group $(P<0.05)$; †significantly greater than ovarian steroids treated group $(P<0.025)$. $E_{2}$, estradiol; $P$, progesterone.

problems have prevented a more widespread usage of this system for studying primary breast cells from surgical specimens. The transplantation take of 262 surgical breast specimens, by far the largest number in a single study, has been reported to be only 6\% (Giovanella et al. 1991), although a much higher take can be accomplished by co-injection with fibroblasts (Romijn 1991), collagen gel (Yang et al. 1994), or Matrigel (Fridman et al. 1991, Mehta et al. 1993). Transplantation of non-malignant breast tissues into nude mice has also been reported (Jensen \& Wellings 1976, Gusterson et al. 1984, McManus \& Welsch 1984). Early studies have demonstrated that administration of exogenous estrogen consistently resulted in increased proliferation of transplanted human breast tissues (McManus \& Welsch 1984). More recent studies (Laidlaw et al. 1995), including our own (Popnikolov et al. 1995a), have confirmed the dose-dependent mitogenic effect of exogenous estrogen on transplanted human cells.

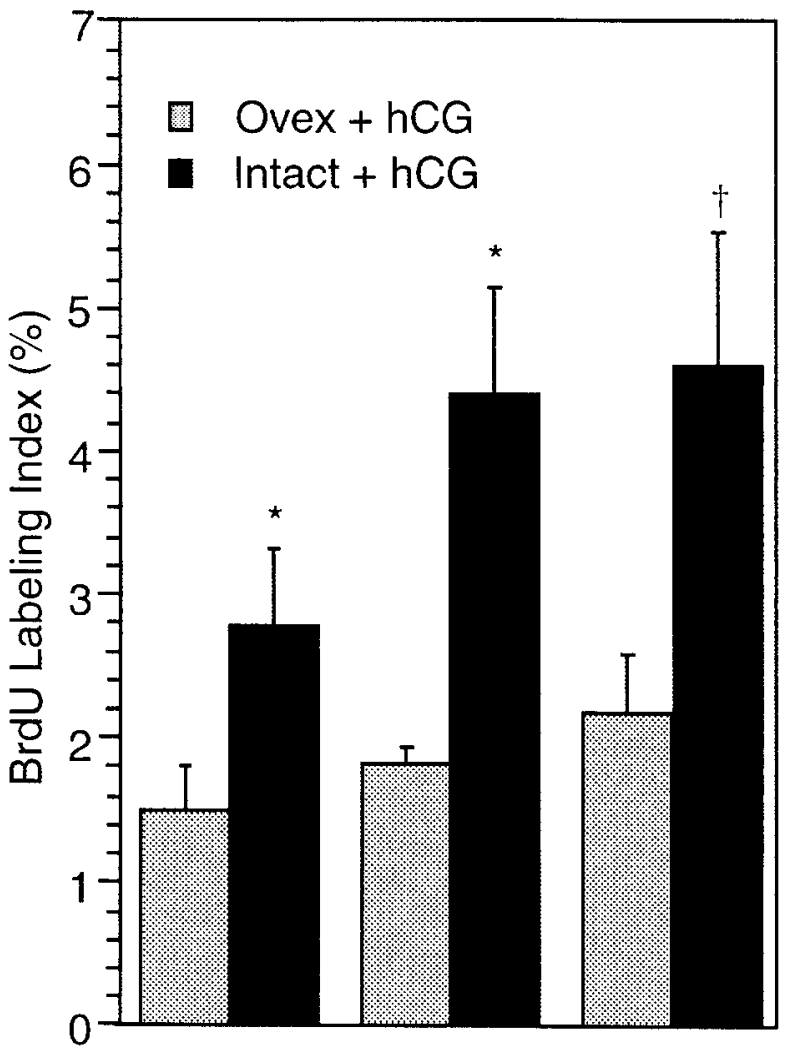

\section{Expt $1 \quad$ Expt $2 \quad$ Expt 3}

Figure 6 Effect of ovariectomy on hCG-induced proliferation of human breast epithelial cells transplanted into nude mice. Each bar represents the mean \pm S.D. of values from three to five gels. For experiment 1 , hCG ( $50 \mathrm{IU} /$ day) was administered for 5 days by injections. For experiments 2 and 3, hCG (1000 IU/pellet) was administered by pellets for 3 days. *Significantly greater than corresponding control $(P<0 \cdot 005)$; †significantly greater than corresponding control $(P<0 \cdot 025)$; ovex - ovariectomy.

In this study, we attempted to determine the effect of the hormonal milieu of pregnancy on the transplanted human cells since the proliferation of human breast epithelial cells is highest during the first trimester of human pregnancy. Since the hormonal changes of pregnancy are too complex to mimic by the administration of known hormones, we provided a similar hormonal environment by mating the host nude mice to undergo pregnancy. Although the hormonal milieu in human pregnancy is certainly different from that in mouse pregnancy, the complex mixture of hormones may be better mimicked in this manner rather than by the administration of known hormones.

In response to the hormonal milieu of the host mouse pregnancy, proliferation of transplanted human cells was observed. The proliferation increased with progression of the pregnancy and reached the maximum level during late 


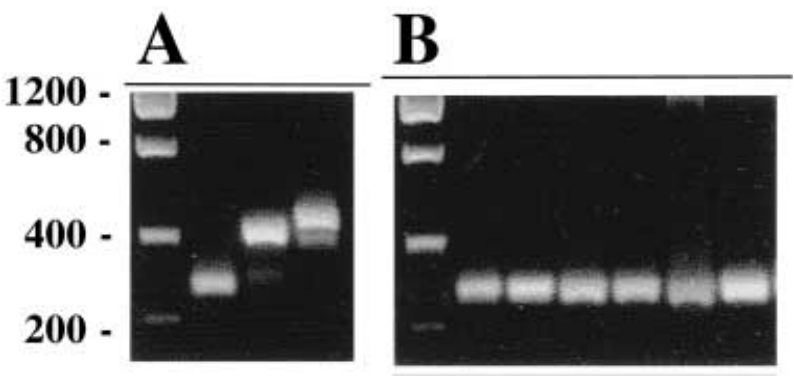

Figure 7 RT-PCR analysis of hCG receptor transcript in normal human breast epithelial cells. (A) Nested (275 bp product shown in left lane) and two semi-nested (435 bp product shown in center lane, and 455 bp product shown in right lane) RT-PCRs demonstrate presence of hCG receptor transcripts in highly enriched epithelial cells dissociated from a reduction mammoplasty specimen. (B) Nested RT-PCR in epithelial cells from six separate reduction mammoplasty specimens.

pregnancy prior to parturition. In order to determine whether additional stimulation could be achieved, the transplanted human cells were exposed to a second cycle of host mouse pregnancy by immediately mating the animal after parturition. This additional exposure of host mouse pregnancy did not result in a further increase of proliferation. In fact, the profile of proliferation during the second cycle was virtually identical to that seen during the first cycle. The reason for the highest proliferation of transplanted human cells during late pregnancy of host mouse right before parturition is not clear, but it is possible that the highest estrogen level present in late mouse pregnancy may be responsible for this. The lower estrogen level in early pregnancy of mouse may not be conducive for the proliferation of human cells. Our previous study demonstrated that a higher estrogen level is required to stimulate proliferation of human breast epithelial cell compared with mouse mammary epithelial cells (Popnikolov et al. 1995a).

The role of hCG in proliferation of normal human breast was also studied since the profile of hCG secretion during the first trimester of human pregnancy coincides with the maximal breast epithelial cell proliferation. Administration of hCG alone stimulated proliferation of human cells in a dose-dependent manner, and could further enhance stimulation achieved with estrogen. However, the hCG effect was dependent on intact ovary since the stimulation did not occur in ovariectomized animals. Although hCG receptor transcripts were detected in human breast epithelial cells, raising the possibility of a direct mitogenic action, the hCG effect observed in this study may have been mediated via the ovary by increased secretion of ovarian steroids.

The effect of hCG has been studied previously by others in rat mammary gland and on normal and tumor human breast cell lines. Injections of hCG in rats have been reported to increase proliferation followed by differentiation of rat mammary gland similar to that seen at pregnancy (Russo et al. 1990). This effect is presumably an indirect one resulting from the stimulatory effect of hCG on the host ovaries to increase secretion of ovarian steroids. However, hCG has also been reported to inhibit proliferation of rat mammary epithelial cells, as well as established human breast cancer cell lines, in culture (Moviglia \& Russo 1984, Alvarado et al. 1994) suggesting a direct effect of hCG. That hCG can directly act at the mammary cell level is also supported by findings showing the presence of hCG receptors in human breast surgical specimens and human breast cancer cell lines (Lojun et al. 1997, Meduri et al. 1997). Our results demonstrating the presence of hCG receptor transcripts in normal human breast epithelial cells from reduction mammoplasty specimens are consistent with the possibility of a direct hCG action at the cellular level, but a lack of hCG effect in ovariectomized hosts clearly demonstrate the importance of intact ovary in mediating the hCG effect.

Both ovarian steroids and pituitary hormones are believed to be necessary for breast development. For example, primary gonadal dysgenesis, as in Turner's syndrome, results in the absence of thelarche, but estrogen therapy can lead to normal breast development (Laurence et al. 1991). Estrogen therapy to patients with secondary estrogen deficiency due to pituitary insufficiency, however, can lead to only limited breast development, suggesting the importance of intact pituitary. Both growth hormone $(\mathrm{GH})$ and prolactin have been implicated as the important pituitary hormone, especially based on animal studies (Imagawa et al. 1990). However, controversy exists over the identity of the hormones from the pituitary gland in humans. There is a report of a woman with pituitary dwarfism with undetectable GH level, as well as a report of a woman treated surgically for removal of pituitary adenoma with no increase in prolactin during pregnancy, both of whom apparently have completed a successful pregnancy and lactation (Laurence et al. 1991). It is possible that $\mathrm{GH}$ and prolactin can replace each other or that other pituitary hormones can replace GH or prolactin. Even gonadotropin, not usually considered as a mammogenic hormone, has been reported to be involved in normal breast development. There has been a report of the effect of estrogen substitution therapy on breast development in girls with hypo- and hyper-gonadotropic hypogonadism (Pertzelan et al. 1982). In the patients with gonadal dysgenesis, in whom the hypothalamic-pituitary function was normal, treatment led to full breast development. However, in isolated gonadotropin deficiency and multiple pituitary hormone deficiency, breast development was incomplete even after 3 years or more of estrogen treatment. Additional studies are necessary to define precisely the hormone(s) from the pituitary gland involved in human breast development during pregnancy. 
In summary, we demonstrated that normal human breast epithelial cells dissociated from reduction mammoplasty specimens can be transplanted into athymic nude mice. These transplanted human cells responded to an altered hormonal milieu of the host nude mice. When the host animal was mated to undergo pregnancy, the transplanted human cells proliferated in response to an altered hormonal environment. The proliferation increased with progression of pregnancy and peaked during late pregnancy prior to parturition. In order to determine whether additional stimulation could be achieved, the transplanted human cells were exposed to a second cycle of host mouse pregnancy by immediately mating the animal after parturition. This additional exposure of host mouse pregnancy however did not result in further increase of proliferation in the transplanted human cells. Administration of hCG, which is highest during the first trimester of human pregnancy and coincides with the maximal breast cell proliferation, also stimulated proliferation of transplanted human cells in a dose-dependent manner and could enhance stimulation achieved with estrogen. Although hCG receptor transcripts were detected in human breast epithelial cells, raising the possibility of a direct mitogenic action, the hCG effect observed in this study may have been mediated via the increased secretion of ovarian steroids since the hCG effect did not occur in ovariectomized animals.

\section{Acknowledgements}

This research was supported by NIH Grants R01DK52323 and CA 49374A. We would like to thank the Cooperative Human Tissue Network Western Division for providing human breast specimens. We gratefully acknowledge the photographic assistance of Jerry Kapler.

\section{References}

Alvarado MV, Alvarado NE, Russo J \& Russo IH 1994 Human chorionic gonadotropin inhibits proliferation and induces expression of inhibin in human breast epithelial cells in vitro [letter]. In Vitro Cellular and Developmental Biology. Animal 30A 4-8.

Fridman R, Kibbey MC, Royce LS, Zain M, Sweeney M, Jicha DL, Yannelli JR, Martin GR \& Kleinman HK 1991 Enhanced tumor growth of both primary and established human and murine tumor cells in athymic mice after coinjection with matrigel. Journal of the National Cancer Institute 83 769-774.

Giovanella BC, Vardeman DM, Williams LJ, Taylor DJ, de Ipolyi PD, Greeff PJ, Stehlin JS, Ullrich A, Cailleau R, Slamon DJ \& Gary HE Jr 1991 Heterotransplantation of human breast carcinomas in nude mice. Correlation between successful heterotransplants, poor prognosis and amplification of the HER-2/neu oncogene. International Journal of Cancer 47 66-71.

Gusterson BA, Williams J, Bunnage H, O'Hare MJ \& Dubois JD 1984 Human breast epithelium transplanted into nude mice. Virchows Archiv. A, Pathology, Anatomy and Histopathology 404 325-333.
Imagawa W, Bandyopadhyay GK \& Nandi S 1990 Regulation of mammary epithelial cell growth in mice and rats. Endocrine Reviews 11 494-523.

Imagawa W, Yang J, Guzman R \& Nandi S 1994 Control of mammary gland development. In The Physiology of Reproduction, edn 2, pp 1033-1063. Eds E Knobil \& JD Neill. New York: Raven.

Jensen H \& Wellings SR 1976 Preneoplastic lesions of the human mammary gland transplanted into the nude athymic mice. Cancer Research 36 2605-2620.

Laidlaw IJ, Clarke RB, Howell A, Owens A, Potten CS \& Anderson E 1995 The proliferation of normal human breast tissue implanted into athymic nude mice is stimulated by estrogen but not progesterone. Endocrinology 136 164-171.

Laurence DJ, Monaghan P \& Gusterson BA 1991 The development of the normal human breast. Oxford Reviews of Reproductive Biology 13 149-174.

Lojun S, Bao S, Lei ZM \& Rao CV 1997 Presence of functional luteinizing hormone/chorionic gonadotropin receptors in human breast cell lines. Implications supporting the premise that hCG protects women against breast cancer. Biology of Reproduction $\mathbf{5 7}$ 1202-1210.

McManus MJ \& Welsch CW 1984 The effect of estrogen, progesterone, thyroxine, and human placental lactogen on DNA synthesis of human breast ductal epithelium maintained in athymic nude mice. Cancer Research 54 1920-1927.

Meduri G, Charnaux N, Loosfelt H, Jolivet A, Spyratos F, Brailly S \& Milgrom E 1997 Luteinizing hormone/human chorionic gonadotropin receptors in breast cancer. Cancer Research $\mathbf{5 7}$ 857-864.

Mehta RR, Graves JM, Hart GD, Shilkaitas A \& Das Goupta TK 1993 Growth and metastasis of human breast carcinomas with matrigel in athymic nude mice. Breast Cancer Research and Treatment 25 65-71.

Moviglia GA \& Russo J 1984 Antimitogenic effect of human chorionic gonadotropin (hCG) on rat mammary epithelial cells in culture. Journal of Cell Biology 99 1439a.

Pertzelan A, Yalon L, Kauli R \& Laron Z 1982 A comparative study of the effect of oestrogen substitution therapy on breast development in girls with hypo- and hypergonadotrophic hypogonadism. Clinical Endocrinology 16 359-368.

Pike MC, Spicer DV, Dahmoush L \& Press MF 1993 Estrogen, progestogens, normal breast cell proliferation, and breast cancer risk. Epidemiologic Reviews 15 17-35.

Popnikolov N, Yang J, Guzman R, Swanson S, Thordarson G, Collins $G$, Talamantes F \& Nandi S $1995 a$ in vivo growth stimulation of collagen gel embedded normal human and mouse primary mammary epithelial cells. Journal of Cell Physiology 163 51-60.

Popnikilov NK, Yang J, Guzman RC \& Nandi S $1995 b$ Reconstituted human normal breast in nude mice using collagen gel or matrigel. Cell Biology International 19 539-546.

Romijn JC 1991 Tumorigenicity. In The Nude Mice in Oncology Research, pp 51-63. Eds E Boven \& E Winograd. Amsterdam: CRS Press.

Rugh R 1990 The Mouse, Its Reproduction and Development. Oxford: Oxford University Press.

Russo IH, Koszalka M \& Russo J 1990 Effect of human chorionic gonadotropin on mammary gland differentiation and carcinogenesis. Carcinogenesis 11 1849-1855.

Soderqvist G, von Schoultz B, Tani E \& Skoog L 1993 Estrogen and progesterone receptor content in breast epithelial cells from healthy women during the menstrual cycle. American Journal of Obstetrics and Gynecology 168 874-879.

Williams G, Anderson E, Howell A, Watson R, Coyne J, Roberts SA \& Potten CS 1991 Oral contraceptive (OCP) use increases proliferation and decreases oestrogen receptor content of epithelial cells in the normal human breast. International Journal of Cancer $\mathbf{4 8}$ $17-35$. 
Yang J, Balakrishnan A, Hamamoto S, Elias JJ, Rosenau W, Beattie CW, Das Grupta TK, Wellings SR \& Nandi S 1987 Human breast epithelial cells in serum-free collagen gel primary culture: growth, morphological and immunocytochemical analysis. Journal of Cell Physiology 133 228-234, 254-255.

Yang J, Guzman R, Popnikolov N, Bandyopadhyay GK, Christov K, Collins G \& Nandi S 1994 Phenotypic characterization of collagen gel embedded primary human breast epithelial cells in nude mice. Cancer Letters 81 117-127.

Yang J, Liu A, Dougherty C, Chen X, Guzman R \& Nandi S 2000a Estrogen and progesterone receptors can be maintained in normal human breast epithelial cells in primary culture and after transplantation into nude mice. Oncology Reports 7 17-21.

Yang J, Liu A, Chiou SK, Guzman R \& Nandi S $2000 b$ Estrogen receptor variants are present in many normal human tissues. International Journal of Molecular Medicine 5 223-227.

Received 27 April 2000

Revised manuscript received 11 August 2000 Accepted 6 November 2000 